\title{
Molecular Epidemiology for Vector Research on Leishmaniasis
}

\author{
Hirotomo Kato $^{1, *}$, Eduardo A. Gomez ${ }^{2}$, Abraham G. Cáceres ${ }^{3,4}$, Hiroshi Uezato ${ }^{5}$, \\ Tatsuyuki Mimori ${ }^{6}$ and Yoshihisa Hashiguchi ${ }^{7}$
}

1 Department of Veterinary Hygiene, Faculty of Agriculture, Yamaguchi University, Yamaguchi 753-8515, Japan

2 Departamento de Oncocercosis, Servicio Nacional de Erradicacion de la Malaria, Ministerio de Salud Publica, Guayaquil 10833, Ecuador; E-Mail: egolandires@yahoo.es

3 Sección de Entomología, Instituto de Medicina Tropical "Daniel A. Carrion”, Facultad de Medicina, Universidad Nacional Mayor de San Marcos, Lima, Lima 1, Perú;

E-Mail: acaceres31@hotmail.com

4 Laboratorio de Entomología, Instituto Nacional de Salud, Lima, Lima 11, Perú

5 Department of Dermatology, Faculty of Medicine, University of the Ryukyus, Okinawa 903-0125, Japan; E-Mail: huezato@med.u-ryukyu.ac.jp

6 Department of Microbiology, School of Health Sciences, Kumamoto University, Kumamoto 862-0976, Japan; E-Mail: mimori@kumamoto-u.ac.jp

7 Department of Parasitology, Kochi Medical School, Kochi University, Kochi 783-8505, Japan; E-Mail: yhashiguchi42@yahoo.co.jp

* Author to whom correspondence should be addressed; E-Mails: katoh@yamaguchi-u.ac.jp; Tel. \& Fax: +81-83-933-5900.

Received: 9 December 2009; in revised form: 3 February 2010 / Accepted: 16 February 2010 / Published: 5 March 2010

\footnotetext{
Abstract: Leishmaniasis is a protozoan disease caused by the genus Leishmania transmitted by female phlebotomine sand flies. Surveillance of the prevalence of Leishmania and responsive vector species in endemic and surrounding areas is important for predicting the risk and expansion of the disease. Molecular biological methods are now widely applied to epidemiological studies of infectious diseases including leishmaniasis. These techniques are used to detect natural infections of sand fly vectors with Leishmania protozoa and are becoming powerful tools due to their sensitivity and specificity. Recently, genetic analyses
} 
have been performed on sand fly species and genotyping using PCR-RFLP has been applied to the sand fly taxonomy. In addition, a molecular mass screening method has been established that enables both sand fly species and natural leishmanial infections to be identified simultaneously in hundreds of sand flies with limited effort. This paper reviews recent advances in the study of sand flies, vectors of leishmaniasis, using molecular biological approaches.

Keywords: Leishmania; sand fly; epidemiology; mass screening

\section{Leishmaniasis}

Leishmaniasis is caused by protozoan parasites belonging to the genus Leishmania, which is further divided into two subgenera, Leishmania and Viannia. Leishmania protozoa are transmitted by the bite of the female phlebotomine sand fly [1,2]. The disease is widely distributed around the world especially in tropical and subtropical areas, affecting at least 12 million people in 88 countries, with another 350 million people at risk [1,2]. Approximately 20 Leishmania species are known to be pathogenic to humans, and the species is the major determinant of clinical outcome (cutaneous, mucocutaneous and visceral forms) [1-3].

Cutaneous leishmaniasis (CL), known as "Oriental Sores" and "Baghdad Boils" in the Old World and "Chiclero's Ulcer" and "Uta" in the New World, is caused by various Leishmania species including Leishmania (Leishmania) major and L. (L.) tropica in the Old World and L. (L.) mexicana, L. (L.) amazonensis, L. (Viannia) braziliensis, L. (V.) guyanensis and L. (V.) peruviana in the New World $[1,2,4]$. Typical CL is characterized by localized refractory skin ulcers or nodules at sites of infection that heal spontaneously leaving life-long scars [1,2]. Other unusual types of CL include leishmaniasis recidiva cutis (LRC) characterized by the development of satellite nodules in or around the scar of a clinically healed lesion after a period of time, diffuse cutaneous leishmaniasis (DCL) producing non-ulcerating chronic nodules over the entire body resembling skin lesions of lepromatous leprosy, and post kala-azar dermal leishmaniasis (PKDL), which can appear on the skin of individuals who have recovered from visceral leishmaniasis (VL) [1,2]. Some 90\% of CL cases are reported to occur in just seven countries; Afghanistan, Algeria, Iran, Saudi Arabia, Syria, Brazil and Peru [2].

Mucocutaneous leishmaniasis (MCL), also known as "Espundia", is endemic in Central and South America, and characterized by destructive metastatic lesions in the mucous membranes of the nose, mouth and throat cavities and surrounding tissues that occur months or years after the onset of the primary cutaneous infection [5]. Although the principal causative agent of MCL is L. (V.) braziliensis, other Leishmania species such as L. (V.) guyanensis, L. (V.) panamensis and L. (L.) amazonensis have been reported to affect mucosal tissues [6-8].

VL, caused by L. (L.) donovani complex, is also known as "Kala azar" or "Dum dum fever". VL is the most severe form of leishmaniasis, and the clinical symptoms include irregular bouts of fever, substantial weight loss, fatigue, anemia and substantial swelling of the liver and spleen [9]. The disease is usually fatal if untreated, and is the second-largest parasitic killer in the world with an 
estimated 500,000 new cases and more than 50,000 deaths each year [2]. Some 90\% of VL cases occur in just five countries; Bangladesh, India, Nepal, Sudan and Brazil [2].

Most leishmaniases are zoonotic diseases that include animal reservoir hosts in the transmission cycle [1]. Humans are considered to be an accidental host, although anthroponotic transmission without animal reservoirs is reported in some Leishmania species [1] (Figure 1).

Figure 1. Schematic life cycle of Leishmania parasites. 1. The sand fly ingests amastigotes during blood feeding. 2. Amastigotes transform into promastigotes. 3. Promastigotes colonize and multiply at the hindgut and midgut of the sand fly. 4. Infective promastigotes (metacyclics) migrate to the anterior part of the gut. 5. The infective stage of promastigotes are transmitted to a mammalian host by the bites of the sand fly. 6. Promastigotes invade host neutrophils. 7. Macrophages are infected by promastigotes directly or through the phagocytosis of infected neutrophils, or infected silently by promastigotes released from apoptotic neutrophils. 8. Promastigotes transform into amastigotes. 9. Amastigotes multiply in infected cells by binary fission. Note: Most Leishmania species are maintained by an animal-to-animal transmission cycle and humans are considered an accidental host (arrow). However, anthroponotic transmission without animal reservoirs is also reported in some Leishmania species (dashed arrow).

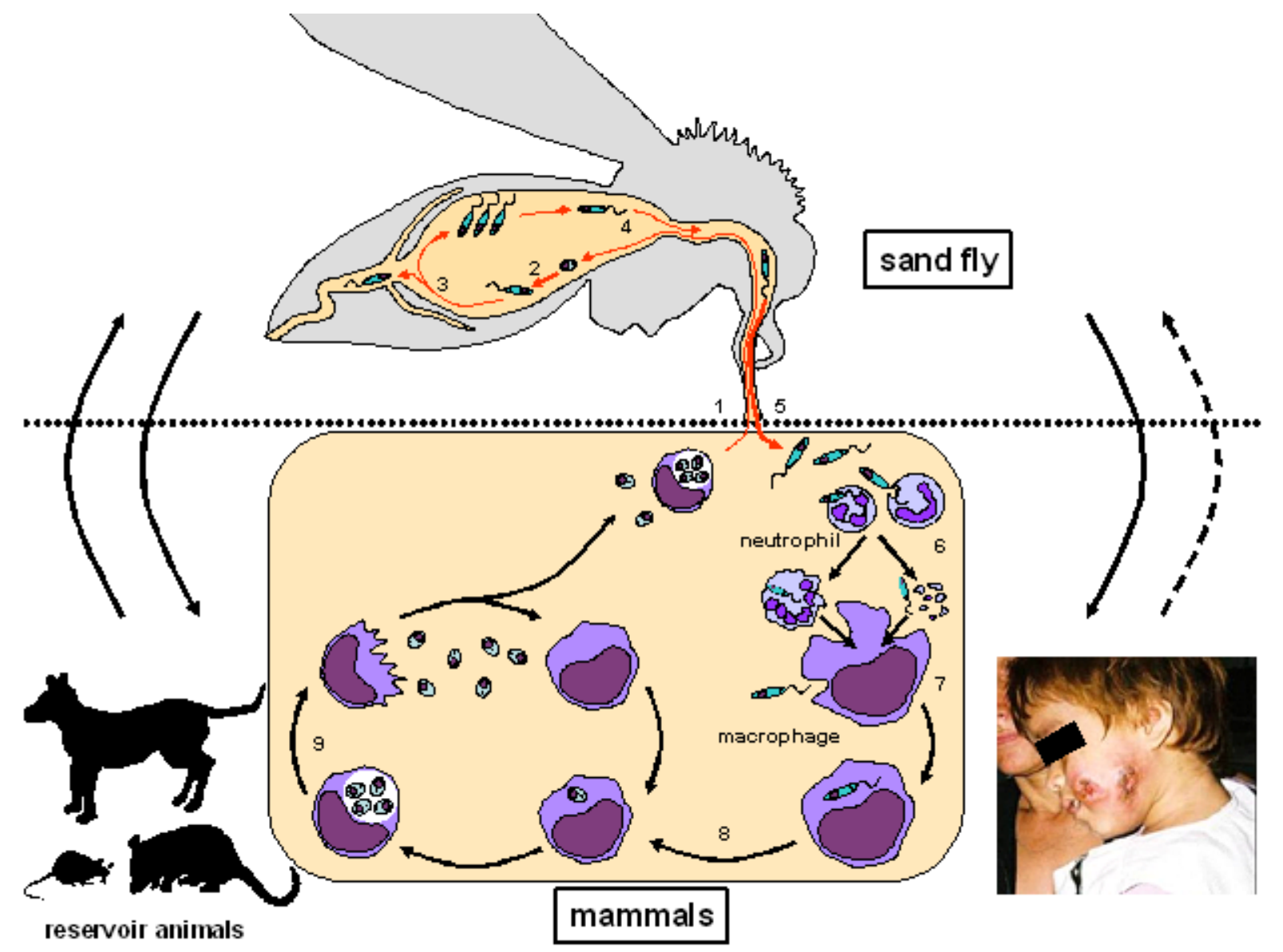

The life cycle of Leishmania species involves two stages; in mammalian hosts, the parasites are observed as an intracellular amastigote with a round or ovoid-shaped and immotile form, but when taken up into the gut of sand flies, they become an extracellular promastigote characterized by a 
spindle-shaped and motile form with an external flagellum [10]. The transformation is triggered by a change in conditions such as temperature and $\mathrm{pH}[11,12]$. The main target of the parasite in mammalian hosts is macrophages, and infections are known to occur in three ways; (1) direct infection, (2) phagocytosis of infected neutrophils by macrophages (the Trojan horse model), and 3) silent infection by parasites released from apoptotic neutrophils [13]. Neutrophils, which are recruited to sites of tissue damage caused by sand fly bites in the initial phase, are considered to ingest the majority of parasites and play a central role in the establishment of the Leishmania infection [13-18] (Figure 1).

\section{Phlebotomine Sand Flies as a Vector of Leishmaniasis}

Phlebotomine sand flies are tiny blood-feeding insects of the family Psychodidae in the order Diptera with a body length of approximately 2-3 $\mathrm{mm}$ [19]. They vary in color from silver-gray to almost black, and fold their wings into a characteristic V-shape when at rest (Figure 2). They are active nocturnally and rest in houses, cellars, caves and gaps among rocks in the daytime. Unlike mosquitoes, they fly feebly and silently, and sneak up on a host using a peculiar hopping motion [20]. Only female flies suck blood for egg production, and the bites are typically painful. To date, approximately 800 sand fly species have been recorded in five major genera; Phlebotomus (94 species) and Sergentomyia (258 species) in the Old World, and Lutzomyia (379 species), Brumptomyia (23 species) and Warileya (5 species) in the New World, and of these, proven vector species of Leishmania protozoa are classified into the genus Phlebotomus and Lutzomyia [20]. The majority of the species play no part in the transmission of leishmaniasis in nature for several reasons; they may not feed on blood from humans and potential reservoir animals, and/or they may be incapable of supporting the development of Leishmania species [20,21]. Less than $10 \%$ of sand flies have been incriminated as vector species of leishmaniasis, and only about 30 species have been demonstrated to have a vectorial capacity [10]. In addition, each vector species can only support the development of and consequently transmit certain species of Leishmania [10,19]. In the susceptible vector, the promastigotes of Leishmania attach to the epithelium of the gut, multiply, and differentiate into the infective metacyclic form, which is transmitted to the mammalian host [21,22] (Figure1). The attachment of the promastigotes to the insect midgut is crucial to the completion of their life cycle in order to avoid excretion when the sand fly defecates [21,22]. The attachment is mediated by lipophosphoglycan (LPG), the major surface glycoconjugate of promastigotes, and the structures are polymorphic among species, suggesting that LPG is the major determinant specifying a vector species [22,23]. The only midgut protein of sand flies shown to interact with Leishmania is PpGalec, a $\beta$-galactoside-binding lectin, found in Phlebotomus (P.) papatasi, a principal vector of L. (L.) major in the Old World [24]. Genomic DNA hybridized with PpGalec was present in P. papatasi and P. duboscqi, both of which transmit L. (L.) major in nature, but absent in $P$. sergenti and $P$. argentipes, vector species of $L$. (L.) tropica and $L$. (L.) donovani, respectively, in the Old World, and Lutzomyia (Lu.) longipalpis and Lu. verrucarum which transmit L. (L.) infantum (previously called L. (L.) chagasi) and L.(V.) peruviana, respectively, in the New World [24]. The result strongly suggests that midgut molecules of sand flies are the key determinant of vectorial competency. 
Figure 2. A blood-sucking phlebotomine sand fly.

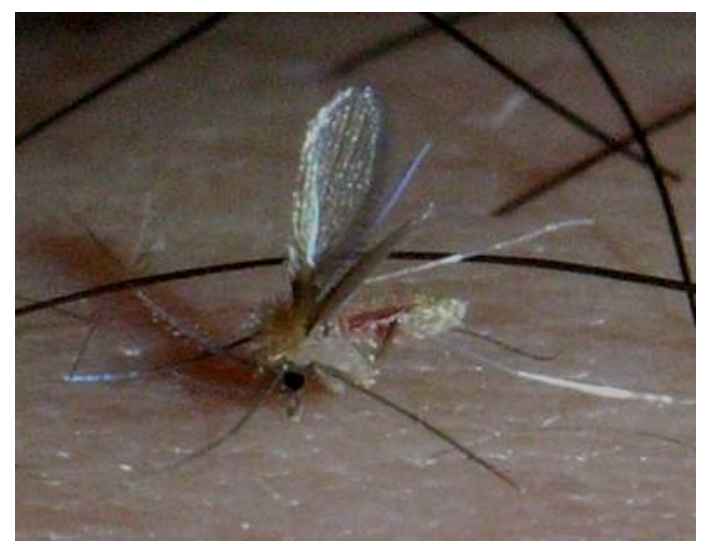

\section{Advances in Sand Fly Taxonomy}

As described, only some of the approximately 800 sand fly species are medically important, and certain sand fly species can transmit only certain species of Leishmania [21,22]. Since the spread of leishmaniases largely depends on the distribution of the vectors, the identification of circulating sand fly species in endemic and surrounding areas is important for predictions of the risk and expansion of the disease. Sand flies are generally identified as adults based on morphologic characteristics, mainly internal structures such as the spermatheca, cibarium and pharynx in females, and terminal genitalia in males $[19,20]$. Other characteristics include the location and intensity of pigmentation of the thorax, and the length ratios of wing veins, and antennal and leg segments [19,20]. Approximately 90 characteristics have been demonstrated as effective descriptors, and these characters are examined and measured on each specimen under a microscope after appropriate preservation and mounting $[19,20]$. Thus, the morphological classification requires considerable skill as well as taxonomic expertise. In addition, the presence of intraspecific variation and cryptic species frequently complicates classifications based on morphological features [25]. Furthermore, damage caused by improper storage and mounting makes the process more difficult or can cause misidentification. Therefore, other characteristics like molecular markers have been explored for the development of simpler and more accurate ways to identify sand flies. Several genetic markers have been used to examine the systematics, relationships and evolution among sand fly species and for population analyses within species [26-52]. Most results of genetic analyses support the generally accepted classification based on morphological characteristics, however, discrepancies exist between the two classifications in several groupings, suggesting the necessity for careful reconsideration of the sand fly taxonomy $[42,51,52]$. With the accumulation of genetic data on sand flies, attempts have been made to establish methods of identification using simple techniques such as the PCR-restriction fragment length polymorphism (RFLP) analysis of $18 \mathrm{~S}$ rRNA genes [33,45-47,50,51]. Although genetic diversity affecting RFLP-patterns was found in some species, the genotyping method was shown to be accurate and easy-to-use for the identification of sand fly species, requiring less expertise and with less risk of different interpretations among researchers than the conventional morphology-based classification [33,45-47,50,51]. It is important to note that this DNA-based technique doesn't require special storage conditions for the specimens, and different methods of preservation such as drying and the use of $70 \%$ ethanol or liquid nitrogen did not affect the quality of the results [33]. In addition, 
damage to samples, which affects the morphologic classification in many cases, does not affect the PCR-RFLP analysis. To date, approximately 400 Lutzomyia and 100 Phlebotomus species have been recorded, and it is impossible to distinguish them all with a PCR-RFLP-based method. Usually, however, not many species coexist in an endemic area. Therefore, the PCR-RFLP-based method targeting several different genes will be a powerful tool for sand fly research as well as studying taxonomy in given leishmaniasis-endemic areas.

Interestingly, several studies suggested differences in vectorial capacity among populations within vector species such as mosquitoes [53,54]. The population structure has been analyzed in the Old World species $P$. papatasi and P. sergenti $[38,39]$ and in the New World species Lu. longipalpis and recently Lu. hartmanni and Lu. ayacuchensis [25,52,55-60]. Heterogeneity of transcribed spacer (ITS) 2 sequences among populations was reported in P. sergenti, the main vector of $L$. (L.) tropica, and an association with vectorial capacity was hypothesized [38]. In addition, remarkable genetic variation among populations was also found in $L u$. longipalpis, the principal vector of $L$. (L.) infantum (=L. (L.) chagasi), on the basis of the mitochondria ND4 gene [55]. On the other hand, an absence of geographic distribution for both ITS2 and mitochondria ND4 genes was reported in P. papatasi, the principal vector of $L$. (L.) major [39], and for ITS1 and ITS2 genes in both Lu. hartmanni and Lu. ayacuchensis, which are the vector species of L. (V.) panamensis and L. (L.) mexicana, respectively [52]. The genetic heterogeneity described in P. sergenti and Lu. longipalpis may be associated with morphological variation that is observed in the two species but not in Lu. hartmanni, Lu. ayacuchensis and $P$. papatasi [39,52,59]. More recently, a correlation between microsatellite markers and geographical origin was described in P. papatasi, suggesting multi-locus microsatellite typing to be effective for population analysis in sand flies [61]. Thus, further extensive study should disclose markers appropriate for population genetics in sand flies, resulting in the elucidation of vectorial capacity among population structures.

\section{Advances in the Detection and Identification of Leishmania Species within Naturally Infected Sand Flies}

Detection and identification of Leishmania species within sand flies are important for predictions of the risk and expansion of the disease in endemic and surrounding areas since the infected species is the major determinant of the clinical outcome in humans [1-3]. The infection of sand flies with Leishmania promastigotes has been examined by the dissection of individual sand flies under a microscope. For this purpose, specimens need to be fresh, and the dissection of tiny sand flies requires a highly skilled technique. The procedure takes a relatively long time, and additionally, a large number of specimens have to be examined to obtain informative data for each area since the infection rate of sand flies with Leishmania is generally very low $(0.01-1 \%)$ even in endemic areas $[62,63]$. To improve on conventional methods, several PCR-based techniques have been developed [45,47,64-73], and infection of Leishmania species within sand flies was identified, e.g., L. (L.) major in P. papatasi [65], L. (L.) infantum in P. major [69] and L. (L.) donovani in P. argentipes [72] in the Old World, and $L$. (L.) mexicana in Lu. ayacuchensis [45,47] and Lu. ovallesi [66], L. (L.) amazonensis in Lu. longipalpis [67,73], L. (L.) infantum chagasi in Lu. longipalpis [67] and Lu. almerioi [73], L. peruviana in Lu. peruensis [47], L. (V.) naiffi in Lu. tortura [48] and L. (V.) braziliensis in 
Lu. ovallesi [66], Lu. gomezi [66] and Lu. neivai [70] in the New World. In most studies, DNA was extracted from pooled sand fly samples or from individual sand flies by use of an expensive kit or by a complicated conventional protocol using proteinase K-containing DNA extraction buffer followed by phenol/chloroform extraction and ethanol precipitation. These methods are sensitive enough to detect Leishmania species within sand flies. However, several improvements were desirable for the analysis of a large number of sand flies with less effort and cost. In addition, it is better to analyze sand flies individually because several species co-exist in most endemic areas and the use of pooled samples may spoil important information on vector epidemiology such as the prevalent sand fly species and the relationships between Leishmania and vector species. Recently, a method of mass screening sand flies for Leishmania infection was established, and its usability for field research confirmed [46,47]. The protocol is represented in Figure 3. With this method, 96 individual samples can be analyzed at once with few processes. The method has a number of advantages: 1) purification of DNA is not required; that is, ethanol-fixed sand fly samples lysed in conventional DNA extraction buffer overnight at $37{ }^{\circ} \mathrm{C}$ without homogenization can be directly used as PCR templates, 2) the sensitivity and specificity are very high; leishmanial DNA is detectable if only one parasite exists in a sample, 3) data on individual sand flies can be obtained, 4) there is minimum risk of DNA loss and contamination among samples because of few processes, and 5) each sample can be used as a template for 100-150 PCRs. In addition, the sand fly species can be identified by molecular biological methods such as PCR-RFLP using the same template DNA if some genetic information is available on the prevalent sand fly species in the given endemic areas. Further, Leishmania species detected within sand flies can be identified by the analysis of leishmanial genes such as the mitochondrial cytochrome $b$ gene [45-48,74-76]. Thus, application of the mass screening method in different areas will provide important information on risk factors, hopefully leading to the control and /or surveillance of leishmaniasis.

Figure 3. A molecular mass screening method for the detection of Leishmania within individual sand flies and identification of both sand fly and Leishmania species.

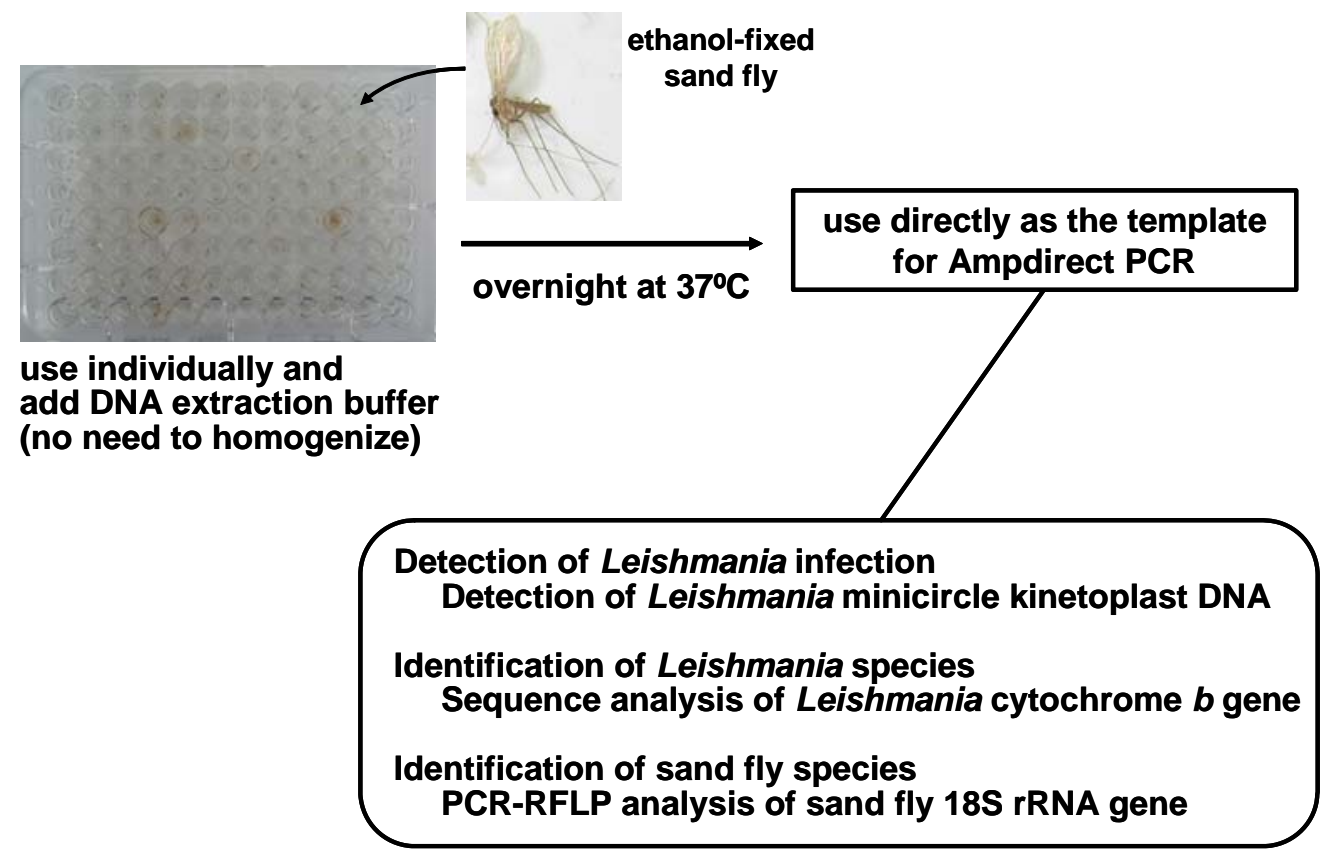




\section{Concluding Remarks}

Molecular biological techniques are now becoming powerful tools for sand fly research. Therefore, more detailed information on the risk factors for leishmaniasis, such as the prevalent sand fly species as well as the seasonal variation in the infection rate and transmission risk, can be accumulated by continuous efforts using such techniques in various endemic areas in different seasons. In addition, elucidation of the relationships between Leishmania and vector species, which requires enormous effort with current methods, by use of molecular methods mentioned, will contribute to not only epidemiological research on leishmaniasis but also basic studies on parasite-vector interactions.

\section{References}

1. Desjeux, P. The increase of risk factors for leishmaniasis worldwide. Trans. R. Soc. Trop. Med. Hyg. 2001, 95, 239-243.

2. Desjeux, P. Leishmaniasis: current situation and new perspectives. Comp. Immunol. Microbiol. Infect. Dis. 2004, 27, 305-318.

3. Choi, C.M.; Lerner, E.A. Leishmaniasis as an emerging infection. J. Invest. Dermatol. Symp. Proc. 2001, 6, 175-182.

4. Grimaldi, G., Jr.; Tesh, R.B.; McMahon-Pratt, D. A review of the geographic distribution and epidemiology of leishmaniasis in the New World. Am. J. Trop. Med. Hyg. 1989, 41, 687-725.

5. Marsden, P.D. Mucosal leishmaniasis (“espundia” Escomel, 1911) Trans. R. Soc. Trop. Med. Hyg. 1986, 80, 859-876.

6. Naiff, R.D.; Talhari, S.; Barrett, T.V. Isolation of Leishmania guyanensis from lesions of the nasal mucosa. Mem. Inst. Oswaldo Cruz 1988, 83, 529-530.

7. Barral, A.; Pedral-Sampaio, D.; Grimaldi, G., Jr.; Momen, H.; McMahon-Pratt, D.; Ribeiro de Jesus, A.; Almeida, R.; Badaro, R.; Barral-Netto, M.; Carvalho, E.M.; Johnson, W.D., Jr. Leishmaniasis in Bahia, Brazil: evidence that Leishmania amazonensis produces a wide spectrum of clinical disease. Am. J. Trop. Med. Hyg. 1991, 44, 536-546.

8. Osorio, L.E.; Castillo, C.M.; Ochoa, M.T. Mucosal leishmaniasis due to Leishmania (Viannia) panamensis in Colombia: clinical characteristics. Am. J. Trop. Med. Hyg. 1998, 59, 49-52.

9. Bryceson, A.D.M. Leishmaniasis. In Manson's Tropical Disease, 20th ed.; Cook, C.C., Ed.; W.B. Saunders Comp. Ltd: London, Philadelphia, Tronto, Sydney and Tokyo, 1996; pp. 1213-1245.

10. Bates, P.A. Transmission of Leishmania metacyclic promastigotes by phlebotomine sand flies. Int. J. Parasitol. 2007, 37, 1097-1106.

11. Bates, P.A.; Rogers, M.E. New insights into the developmental biology and transmission mechanisms of Leishmania. Curr. Mol. Med. 2004, 4, 601-609.

12. Kamhawi, S. Phlebotomine sand flies and Leishmania parasites: friends or foes? Trends Parasitol. 2006, 22, 439-445.

13. Peters, N.C.; Sacks, D.L. The impact of vector-mediated neutrophil recruitment on cutaneous leishmaniasis. Cell. Microbiol. 2009, 11, 1290-1296.

14. Laskay, T.; van Zandbergen, G.; Solbach, W. Neutrophil granulocytes-Trojan horses for Leishmania major and other intracellular microbes? Trends Microbiol. 2003, 11, 210-214. 
15. Ribeiro-Gomes, F.L.; Otero, A.C.; Gomes, N.A.; Moniz-De-Souza, M.C.; Cysne-Finkelstein, L.; Arnholdt, A.C.; Calich, V.L.; Coutinho, S.G.; Lopes, M.F.; DosReis, G.A. Macrophage interactions with neutrophils regulate Leishmania major infection. J. Immunol. 2004, 172, 4454-4462.

16. van Zandbergen, G.; Klinger, M.; Mueller, A.; Dannenberg, S.; Gebert, A.; Solbach, W.; Laskay, T. Cutting edge: neutrophil granulocyte serves as a vector for Leishmania entry into macrophages. J. Immunol. 2004, 173, 6521-6525.

17. Peters, N.C.; Egen, J.G.; Secundino, N.; Debrabant, A.; Kimblin, N.; Kamhawi, S.; Lawyer, P.; Fay, M.P.; Germain, R.N.; Sacks, D. In vivo imaging reveals an essential role for neutrophils in leishmaniasis transmitted by sand flies. Science 2008, 321, 970-974.

18. Jochim, R.C.; Teixeira, C. Leishmania commandeers the host inflammatory response through neutrophils. Trends Parasitol. 2009, 25, 145-147.

19. Young, D.G.; Duncan, M.A. Guide to the identification and geographic distribution of Lutzomyia sand flies in Mexico, the West Indies, Central and South America (Diptera: Psychodidae), Memoirs of the American Entomological Institute, 54, Associated Publishers-American Entomological Institute, Gainsville, FL, USA, 1994.

20. Munstermann, L.E. Phlebotomine sand flies, the Psychodidae. In Biology of Disease Vectors, 2nd ed.; Marquardt, W.C., Black, W.C., Freier, J.E., Hagedorn, H.H., Hemingway, J., Higgs, S., James, A.A., Kondratieff, B., Moore, C.G., Eds.; Elsevier: San Diego, CA, USA, 2004; pp. 141-151.

21. Killick-Kendrick, R. The biology and control of phlebotomine sand flies. Clin. Dermatol. 1999, 17, 279-289.

22. Sacks, D.L. Leishmania-sand fly interactions controlling species-specific vector competence. Cell. Microbiol. 2001, 3, 189-196.

23. Sacks, D.L.; Modi, G.; Rowton, E.; Späth, G.; Epstein, L.; Turco, S.J.; Beverley, S.M. The role of phosphoglycans in Leishmania-sand fly interactions. Proc. Natl. Acad. Sci. USA 2000, 97, 406-411.

24. Kamhawi, S.; Ramalho-Ortigao, M.; Pham, V.M.; Kumar, S.; Lawyer, P.G.; Turco, S.J.; Barillas-Mury, C.; Sacks, D.L.; Valenzuela, J.G. A role for insect galectins in parasite survival. Cell 2004, 119, 329-341.

25. Bauzer, L.G.; Souza, N.A.; Maingon, R.D.; Peixoto, A.A. Lutzomyia longipalpis in Brazil: a complex or a single species? A mini-review. Mem. Inst. Oswaldo Cruz 2007, 102, 1-12.

26. Ready, P.D.; Smith, D.F.; Killick-Kendrick, R. DNA hybridizations on squash-blotted sandflies to identify both Phlebotomus papatasi and infecting Leishmania major. Med. Vet. Entomol. 1988, 2, 109-116.

27. Ready, P.D.; Lainson, R.; Shaw, J.J.; Souza, A.A. DNA probes for distinguishing Psychodopygus wellcomei from Psychodopygus complexus (Diptera:Psychodidae). Mem. Inst. Oswaldo Cruz 1991, 86, 41-49.

28. Ready, P.D.; de Souza, A.A.; Rebelo, J.M.; Day, J.C.; Silveira, F.T.; Campbell-Lendrum, D.; Davies, C.R.; Costa, J.M. Phylogenetic species and domesticity of Lutzomyia whitmani at the southeast boundary of Amazonian Brazil. Trans. R. Soc. Trop. Med. Hyg. 1998, 92, 159-160. 
29. Booth, D.R.; Ready, P.D.; Smith, D.F. Retrotransposons and evolution in phlebotomines. Parassitologia 1991, 33, 105-112.

30. Booth, D.R.; Ready, P.D.; Smith, D.F. Isolation of non-LTR retrotransposon reverse transcriptase-like sequences from phlebotomine sandflies. Insect Mol. Biol. 1994, 3, 89-96.

31. Booth, D.R.; Ready, P.D.; Smith, D.F. Evolution of multiple families of non-LTR retrotransposons in phlebotomine sandflies. Genet. Res. 1996, 67, 227-237.

32. Esseghir, S.; Ready, P.D.; Killick-Kendrick, R.; Ben-Ismail, R. Mitochondrial haplotypes and phylogeography of Phlebotomus vectors of Leishmania major. Insect Mol. Biol. 1997, 6, 211-225.

33. Aransay, A.M.; Scoulica, E.; Chaniotis, B.; Tselentis, Y. Typing of sand flies from Greece and Cyprus by DNA polymorphism of 18S rRNA gene. Insect Mol. Biol. 1999, 8, 179-184.

34. Aransay, A.M.; Scoulica, E.; Tselentis, Y.; Ready, P.D. Phylogenetic relationships of phlebotomine sandflies inferred from small subunit nuclear ribosomal DNA. Insect Mol. Biol. 2000, 9, 157-168.

35. Aransay, A.M.; Ready, P.D.; Morillas-Marquez, F. Population differentiation of Phlebotomus perniciosus in Spain following postglacial dispersal. Heredity 2003, 90, 316-325.

36. Campbell-Lendrum, D.H.; Brandão-Filho, S.P.; Pinto, M.C.; Vexenat, A.; Ready, P.D.; Davies, C.R. Domesticity of Lutzomyia whitmani (Diptera: psychodidae) populations: field experiments indicate behavioural differences. Bull. Entomol. Res. 2000, 90, 41-48.

37. Di Muccio, T.; Marinucci, M.; Frusteri, L.; Maroli, M.; Pesson, B.; Gramiccia, M. Phylogenetic analysis of Phlebotomus species belonging to the subgenus Larroussius (Diptera, psychodidae) by ITS2 rDNA sequences. Insect Biochem. Mol. Biol. 2000, 30, 387-393.

38. Depaquit, J.; Ferté, H.; Léger, N.; Lefranc, F.; Alves-Pires, C.; Hanafi, H.; Maroli, M.; Morillas-Marquez, F.; Rioux, J.A.; Svobodova, M.; Volf, P. ITS 2 sequences heterogeneity in Phlebotomus sergenti and Phlebotomus similis (Diptera, Psychodidae): possible consequences in their ability to transmit Leishmania tropica. Int. J. Parasitol. 2002, 32, 1123-1131.

39. Depaquit, J.; Lienard, E.; Verzeaux-Griffon, A.; Ferté, H.; Bounamous, A.; Gantier, J.C.; Hanafi, H.A.; Jacobson, R.L.; Maroli, M.; Moin-Vaziri, V.; Müller, F.; Ozbel, Y.; Svobodova, M.; Volf, P.; Léger, N. Molecular homogeneity in diverse geographical populations of Phlebotomus papatasi (Diptera, Psychodidae) inferred from ND4 mtDNA and ITS2 rDNA epidemiological consequences. Infect. Genet. Evol. 2008, 8, 159-170.

40. Testa, J.M.; Montoya-Lerma, J.; Cadena, H.; Oviedo, M.; Ready P.D. Molecular identification of vectors of Leishmania in Colombia: mitochondrial introgression in the Lutzomyia townsendi series. Acta Trop. 2002, 84, 205-218.

41. Torgerson, D.G.; Lampo, M.; Velazquez, Y.; Woo, P.T. Genetic relationships among some species groups within the genus Lutzomyia (Diptera: Psychodidae). Am. J. Trop. Med. Hyg. 2003, 69 , 484-493.

42. Beati, L.; Caceres, A.G.; Lee, J.A.; Munstermann, L.E. Systematic relationships among Lutzomyia sand flies (Diptera: Psychodidae) of Peru and Colombia based on the analysis of $12 \mathrm{~S}$ and 28S ribosomal DNA sequences. Int. J. Parasitol. 2004, 34, 225-234. 
43. Yahia, H.; Ready, P.D.; Hamdani, A.; Testa, J.M.; Guessous-Idrissi, N. Regional genetic differentiation of Phlebotomus sergenti in three Moroccan foci of cutaneous leishmaniasis caused by Leishmania tropica. Parasite 2004, 11, 189-199.

44. Pesson, B.; Ready, J.S.; Benabdennbi, I.; Martín-Sánchez, J.; Esseghir, S.; Cadi-Soussi, M.; Morillas-Marquez, F.; Ready, P.D. Sandflies of the Phlebotomus perniciosus complex: mitochondrial introgression and a new sibling species of $P$. longicuspis in the Moroccan Rif. Med. Vet. Entomol. 2004, 18, 25-37.

45. Kato, H.; Uezato, H.; Katakura, K.; Calvopiña, M.; Marco, J.D.; Barroso, P.A.; Gomez, E.A.; Mimori, T.; Korenaga, M.; Iwata, H.; Nonaka, S.; Hashiguchi, Y. Detection and identification of Leishmania species within naturally infected sand flies in the Andean areas of Ecuador by a polymerase chain reaction. Am. J. Trop. Med. Hyg. 2005, 72, 87-93.

46. Kato, H.; Uezato, H.; Gomez, E.A.; Terayama,Y.; Calvopiña, M.; Iwata, H.; Hashiguchi, Y. Establishment of a mass screening method of sand fly vectors for Leishmania infection by molecular biological methods. Am. J. Trop. Med. Hyg. 2007, 77, 324-329.

47. Kato, H.; Cáceres, A.G.; Gomez, E.A.; Mimori, T.; Uezato, H.; Marco, J.D.; Barroso, P.A.; Iwata, H.; Hashiguchi, Y. Molecular mass screening to incriminate sand fly vectors of Andean-type cutaneous leishmaniasis in Ecuador and Peru. Am. J. Trop. Med. Hyg. 2008, 79, 719-721.

48. Kato, H.; Gomez, E.A.; Yamamoto, Y.; Calvopiña, M.; Guevara, A.G.; Marco, J.D.; Barroso, P.A.; Iwata, H.; Hashiguchi, Y. Natural infection of Lutzomyia tortura with Leishmania (Viannia) naiffi in an Amazonian area of Ecuador. Am. J. Trop. Med. Hyg. 2008, 79, 438-440.

49. Barón, S.; Martín-Sánchez, J.; Gállego, M.; Morales-Yuste, M.; Boussaa, S.; Morillas-Márquez, F. Intraspecific variability (rDNA ITS and mtDNA Cyt b) of Phlebotomus sergenti in Spain and Morocco. Acta Trop. 2008, 107, 259-267.

50. Barroso, P.A.; Marco, J.D.; Kato, H.; Tarama, R.; Rueda, P.; Cajal, S.P.; Basombrío, M.A.; Korenaga, M.; Taranto, N.J.; Hashiguchi, Y. The identification of sand fly species, from an area of Argentina with endemic leishmaniasis, by the PCR-based analysis of the gene coding for $18 \mathrm{~S}$ ribosomal RNA. Ann. Trop. Med. Parasitol. 2007, 101, 247-253.

51. Terayama, Y.; Kato, H.; Gomez, E.A.L.; Uezato, H.; Calvopiña, M.; Iwata, H.; Hashiguchi, Y. Molecular typing of sand fly species (Diptera, Psychodidae, Phlebotominae) from areas endemic for leishmaniasis in Ecuador by PCR-RFLP of $18 \mathrm{~S}$ ribosomal RNA gene. J. Vet. Med. Sci. 2008, 70, 907-913.

52. Kuwahara, K.; Kato, H.; Gomez, E.A.; Uezato, H.; Mimori, T.; Yamamoto, Y.I.; Calvopiña, M.; Cáceres, A.G.; Iwata, H.; Hashiguchi, Y. Genetic diversity of ribosomal RNA internal transcribed spacer sequences in Lutzomyia species from areas endemic for New World cutaneous leishmaniasis. Acta Trop. 2009, 112, 131-136.

53. Krzywinski, J.; Besansky. N.J. Molecular systematics of Anopheles: from subgenera to subpopulations. Annu. Rev. Entomol. 2003, 48, 111-139.

54. Obsomer, V.; Defourny, P.; Coosemans, M. The Anopheles dirus complex: spatial distribution and environmental drivers. Malar. J. 2007, 6, 26.

55. Soto, S.I.; Lehmann, T.; Rowton, E.D.; Vélez, B.I.D.; Porter, C.H. Speciation and population structure in the morphospecies Lutzomyia longipalpis (Lutz \& Neiva) as derived from the mitochondrial ND4 gene. Mol. Phylogenet. Evol. 2001, 18, 84-93. 
56. Bottecchia, M.; Oliveira, S.G.; Bauzer, L.G.; Souza, N.A.; Ward, R.D.; Garner, K.J.; Kyriacou, C.P.; Peixoto, A.A. Genetic divergence in the cacophony IVS6 intron among five Brazilian populations of Lutzomyia longipalpis. J. Mol. Evol. 2004, 58, 754-761.

57. Bauzer, L.G.; Souza, N.A.; Ward, R.D.; Kyriacou, C.P.; Peixoto, A.A. The period gene and genetic differentiation between three Brazilian populations of Lutzomyia longipalpis. Insect. Mol. Biol. 2002, 11, 315-323.

58. Bauzer, L.G.; Gesto, J.S.; Souza, N.A.; Ward, R.D.; Hamilton, J.G.; Kyriacou, C.P.; Peixoto, A.A. Molecular divergence in the period gene between two putative sympatric species of the Lutzomyia longipalpis complex. Mol. Biol. Evol. 2002, 19, 1624-1627.

59. Maingon, R.D.; Ward, R.D.; Hamilton, J.G.; Bauzer, L.G.; Peixoto, A.A. The Lutzomyia longipalpis species complex: does population sub-structure matter to Leishmania transmission? Trends Parasitol. 2008, 24, 2-7.

60. Lins, R.M.; Souza, N.A.; Peixoto, A.A. Genetic divergence between two sympatric species of the Lutzomyia longipalpis complex in the paralytic gene, a locus associated with insecticide resistance and lovesong production. Mem. Inst. Oswaldo Cruz 2008, 103, 736-740.

61. Hamarsheh, O.; Presber, W.; Yaghoobi-Ershadi, M.R.; Amro, A.; Al-Jawabreh, A.; Sawalha, S.; Al-Lahem, A.; Das, M.L.; Guernaoui, S.; Seridi, N.; Dhiman, R.C.; Hashiguchi, Y.; Ghrab, J.; Hassan, M.; Schönian, G. Population structure and geographical subdivision of the Leishmania major vector Phlebotomus papatasi as revealed by microsatellite variation. Med. Vet. Entomol. 2009, 23, 69-77.

62. Hashiguchi, Y.; Gomez, E.A.L. A review of leishmaniasis in Ecuador. Bull. Pan Am. Hlth. Org. 1991, 25, 64-76.

63. Hashiguchi, Y. Leishmaniasis. In Progress of Medical Parasitology in Japan, Otsuru, M., Kamegai, S., Hayashi, S., Eds.; Megro Parasitological Museum, Tokyo, Japan, 2003; Volume 7 , pp. 537-553.

64. Aransay, A.M.; Scoulica, E.; Tselentis, Y. Detection and identification of Leishmania DNA within naturally infected sand flies by seminested PCR on minicircle kinetoplast DNA. Appl. Environ. Microbiol. 2000, 66, 1933-1938.

65. Parvizi, P.; Mauricio, I.; Aransay, A.M.; Miles, M.A.; Ready, P.D. First detection of Leishmania major in peridomestic Phlebotomus papatasi from Isfahan province, Iran: comparison of nested PCR of nuclear ITS ribosomal DNA and semi-nested PCR of minicircle kinetoplast DNA. Acta Trop. 2005, 93, 75-83.

66. Jorquera, A.; González, R.; Marchán-Marcano, E.; Oviedo, M.; Matos, M.; Multiplex-PCR for detection of natural Leishmania infection in Lutzomyia spp. captured in an endemic region for cutaneous leishmaniasis in state of Sucre, Venezuela. Mem. Inst. Oswaldo Cruz 2005, 100, 45-48.

67. Paiva, B.R.; Secundino, N.F.; Nascimento, J.C.; Pimenta, P.F.; Galati, E.A.; Junior, H.F.; Malafronte, R.S. Detection and identification of Leishmania species in field-captured phlebotomine sandflies based on mini-exon gene PCR. Acta Trop. 2006, 99, 252-259.

68. Córdoba-Lanús, E.; De Grosso, M.L.; Piñero, J.E.; Valladares, B.; Salomón, O.D. Natural infection of Lutzomyia neivai with Leishmania spp. in northwestern Argentina. Acta Trop. 2006, $98,1-5$. 
69. Azizi, K.; Rassi, Y.; Javadian, E.; Motazedian, M.H.; Asgari, Q.; Yaghoobi-Ershadi, M.R. First detection of Leishmania infantum in Phlebotomus (Larroussius) major (Diptera: Psychodidae) from Iran. J. Med. Entomol. 2008, 45, 726-731.

70. Pita-Pereira, D.; Souza, G.D.; Zwetsch, A.; Alves, C.R.; Britto, C.; Rangel, E.F. First report of Lutzomyia (Nyssomyia) neivai (Diptera: Psychodidae: Phlebotominae) naturally infected by Leishmania (Viannia) braziliensis in a periurban area of south Brazil using a multiplex polymerase chain reaction assay. Am. J. Trop. Med. Hyg. 2009, 80, 593-595.

71. Silva, E.A.; Andreotti, R.; Dias, E.S.; Barros, J.C.; Brazuna, J.C. Detection of Leishmania DNA in phlebotomines captured in Campo Grande, Mato Grosso do Sul, Brazil. Exp. Parasitol. 2008, 119, 343-348.

72. Pandey, K.; Pant, S.; Kanbara, H.; Shuaibu, M.N.; Mallik, A.K.; Pandey, B.D.; Kaneko, O.; Yanagi, T. Molecular detection of Leishmania parasites from whole bodies of sandflies collected in Nepal. Parasitol. Res. 2008, 103, 293-297.

73. Savani, E.S.; Nunes, V.L.; Galati, E.A.; Castilho, T.M.; Zampieri, R.A.; Floeter-Winter, L.M. The finding of Lutzomyia almerioi and Lutzomyia longipalpis naturally infected by Leishmania spp. in a cutaneous and canine visceral leishmaniases focus in Serra da Bodoquena, Brazil. Vet. Parasitol. 2009, 160, 18-24.

74. Luyo-Acero, G.; Uezato, H.; Oshiro, M.; Kariya, K.; Katakura, K.; Gomez, E.A.L.; Hashiguchi, Y.; Nonaka, S. Sequence variation of the cytochrome $b$ gene of various human infecting members of the genus Leishmania and their pathology. Parasitol. 2004, 128, 483-491.

75. Marco, J.D.; Bhutto, A.M.; Soomro, F.R.; Baloch, J.H.; Barroso, P.A.; Kato, H.; Uezato, H.; Katakura, K.; Korenaga, M.; Nonaka, S.; Hashiguchi, Y. Multilocus enzyme electrophoresis and cytochrome $b$ gene sequencing-based identification of Leishmania isolates from different foci of cutaneous leishmaniasis in Pakistan. Am. J. Trop. Med. Hyg. 2006, 75, 261-266.

76. Marco, J.D.; Uezato, H.; Mimori, T.; Barroso, P.A.; Korenaga, M.; Nonaka, S.; Basombrio, M.A.; Taranto, N.J.; Hashiguchi, Y. Are cytochrome $b$ gene sequencing and polymorphism-specific polymerase chain reaction as reliable as multilocus enzyme electrophoresis for identifying Leishmania spp. from Argentina? Am. J. Trop. Med. Hyg. 2006, 75, 256-260.

(C) 2010 by the authors; licensee Molecular Diversity Preservation International, Basel, Switzerland. This article is an open-access article distributed under the terms and conditions of the Creative Commons Attribution license (http://creativecommons.org/licenses/by/3.0/). 